\title{
Adaptive Traffic Light Control Based on Actual Condition Using Google Map API
}

\author{
Adi Sabwa Isti Besari Arkanuddin ${ }^{1}$, Selo Sulistyo ${ }^{2}$, Anugerah Galang Persada ${ }^{3}$
}

\begin{abstract}
Traffic congestion is one of the main problems in transportation sector and it causes a lot of drawbacks to public. The traffic light system is used to reduce the level of occurring traffic congestion. Generally, the available traffic light systems use a fixed time setting. This old traffic control system is no longer able to manage the ever-changing traffic conditions effectively and efficiently, causing a long queue of vehicles. To overcome this problem, a traffic light control system that can adapt to actual conditions of road density and can run automatically is offered. This system utilizes Google Map API as a road density data source. The result of this study is a traffic control system that can adjust the green light time duration based on the obtained density values and density trends, simulation of this adaptive system as well as simulation results analysis. A prototype of this adaptive control system was also produced in this study.
\end{abstract}

Keywords - Traffic Lights, Adaptive, Google Map API, Green Light Time Duration, Density.

\section{INTRODUCTION}

Indonesia is the fourth most populous country in the world, with a total population of 265 million [1]. Besides creating positive impacts, this large population also creates many negative consequences. One of the them is traffic congestion. Traffic congestion commonly occurs in areas with high population density and a high percentage of vehicles [2]. This high level of traffic congestion has brought many negative effects for society, either financial, time, or physiological losses.

One way to reduce the occurring traffic congestion is to control the crossroads using traffic lights. The use of traffic lights is intended to prevent traffic congestion due to irregular vehicles. Generally, traffic lights in Indonesia still operate on fixed cycles. [3]. In fact, the old regulatory system can no longer regulate traffic flows at the crossroads effectively due to uncertain and ever-changing road density conditions. This allows an ineffective traffic flow control because of the greentime that is not in accordance with the occurring vehicles queue [3]. To overcome this problem, an adaptive traffic light control system that can regulate traffic according to the actual conditions of the highway is utilized, so that the road can be used optimally [4].

${ }^{1}$ Department of Electrical and Information Engineering, Faculty of Engineering, Universitas Gadjah Mada, Jl. Grafika No. 2 UGM Campus 55284 Yogyakarta Indonesia (e-mail: adi.sabwa.i@mail.ugm.ac.id)

${ }^{2,3}$ Lecturer, Department of Electrical and Information Engineering, Faculty of Engineering, Universitas Gadjah Mada, Jl. Grafika No. 2 UGM Campus 55284 Yogyakarta Indonesia (phone: 0274-552305; fax: 0274-552305; e-mail²: selo@ugm.ac.id, e-mail ${ }^{3}$ : galang@ugm.ac.id)
One of the main elements in this adaptive system is a data gathering process of actual conditions from the controlled crossroads. Existing adaptive systems carried out data collection on road density using varying ways, such as using sensor technology, radar technology, video technology, and wireless communication technology [5]. This existing data collecting method still has some shortcomings, for example there is a large amount of costs required for installation and equipment maintenance.

To get this problem under control, an Internet of Things (IoT) system has been used as a means to obtain road density data. Advantage of using this IoT is its low cost and its highest development, particularly for complex transportation systems.

This paper aims to create an adaptive traffic lights control systems that is able to automatically adjust the traffic lights duration according to road conditions using Google Map API as its data source. This control system was tested by conducting simulation and doing analysis on the obtained simulation results.

\section{AdAPTIVE TrAfFiC Lights CONTROL System}

Many researches have discussed a topic similar to the topic discussed in this paper, i.e., an adaptive traffic lights control system. In this section, discussions on several previous researches discussing this topic in the last few years are presented.

Reference [3] discusses the design of adaptive traffic systems that can adjust the green light on based on the input data of the given road. Changes made by a control system in a form of fuzzy logic control. Data was retrieved by using sensors at managed junctions and other interconnected intersections. The provided result is a method or algorithm to determine the duration of the green light.

Another study has developed a Vehicle to Infrastructure (V2I) based adaptive traffic light system that changes based on vehicle speed at an intersection [6]. The designed system consists of three modules: (1) a vehicle module to collect car speed data using On-Board Diagnostic (OBD) device; (2) a ZigBee communication module for data transmission; and (3) a control module to provide instructions to the lamp based on analysis results of vehicle speed information obtained using an algorithm that has been designed.

Reference [7] designed an Adaptive Traffic Light Control System (ATLCS) using infrared sensors for density data collection. Data was used as a reference to determine time duration of the lamp. In an emergency, the system will give a green signal for a road with an emergency condition and red signal for other roads.

Another researcher examined an adaptive traffic light system that uses wireless sensor networks [8]. The research 


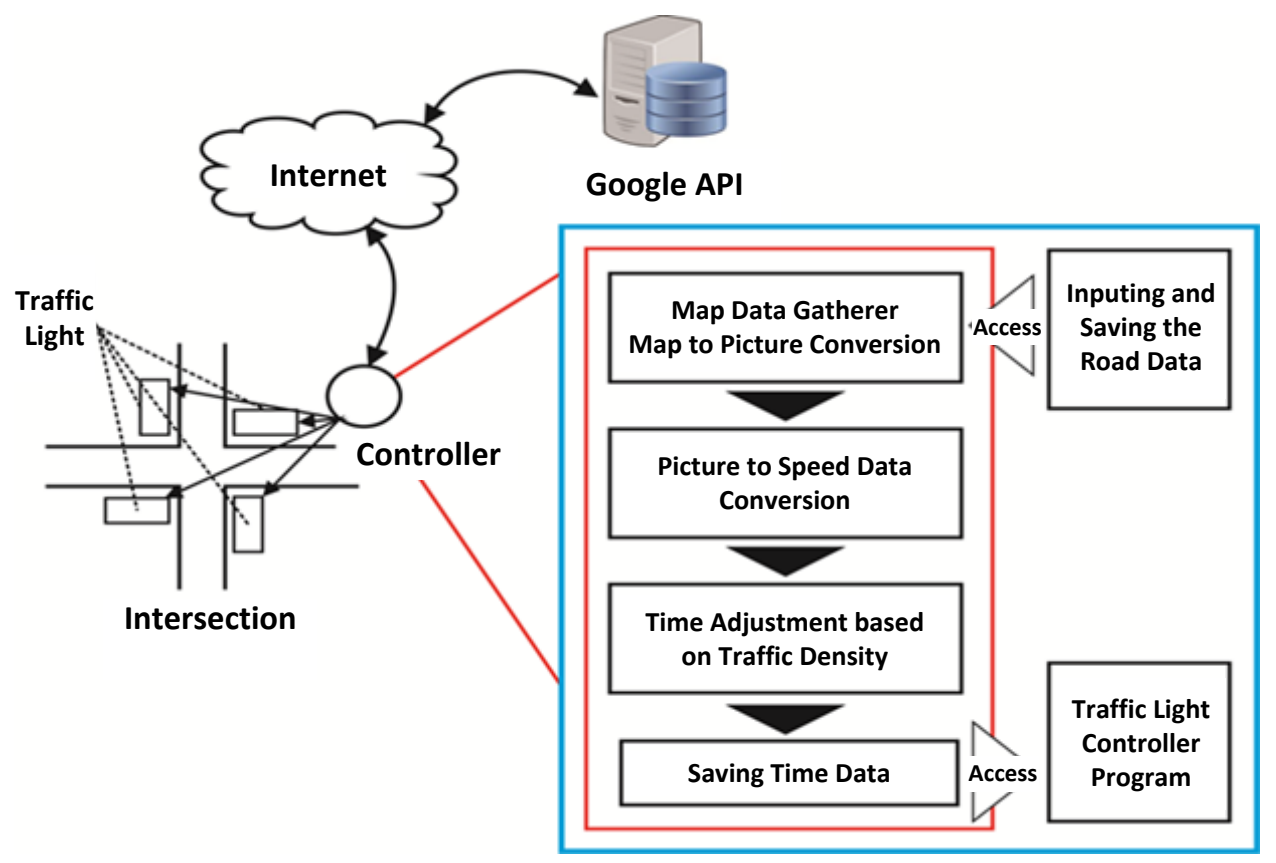

Fig. 1 System architecture.

focus was more on the traffic control algorithm. The system used a magnetic sensor as an input receiver in a form of waiting time and queue length.

\section{MOdEL OF AN AdAPTIVE SySTEM}

\section{A. Basic Concepts and Architecture of Adaptive Control Systems}

This adaptive traffic lights control system was designed with the ability to adjust green-time duration in an intersection based on actual conditions of road density. The system accessed road density data using Google Map API based on road data provided by users.

A system architecture is a series describing an arrangement of system's elements and how they work. The system architecture of this adaptive traffic light control system is divided into several parts, namely controllers, traffic lights, and internet connections to the Google API data server as displayed on the pad. The focus of this paper is the controlling part of this adaptive system. The controller's function is to retrieve density data from Google API server through internet connections, then utilize it as a reference to change time duration on the traffic lights. The control system software has been designed to be able to be used in various types of intersections for example 3way junctions, four-way intersections or others.

The system architecture consists of two parts, software and hardware, shown in Fig. 1. The system's hardware is in form of a traffic light control series consisting of traffic lights, Raspberry $\mathrm{Pi}$, relay module, and connections to the internet, as well as supporting parts such as LCD, mouse and keyboards. System software was developed using the Python programming language. This software consists of six main modules, namely road data input module, data gathering module, data processing module, time adjustment module, time adjustment application module, and traffic light control module.

\section{B. System Flowchart}

System flowchart is a series that describes activities occurring in this adaptive traffic lights control system. This flowchart was designed based on the system architecture that had been made. This traffic control system is generally shown in Fig. 2.

System's activities in this control system flowchart can be divided into three main parts, namely data input process, data processing process, and lamp control process. The data input process was started at the beginning before the other two processes were carried out. This process was carried out to obtain the intersection data that will be controlled, in a form of coordinate and monitored road side data.

Data processing and lamp control processes were designed to be able to run simultaneously at the same tame. This data processing process was divided into three sections, namely data gathering section, data processing section, and time adjustment section. The function of data gathering section was to access density map data of each road side at the intersection that was set using the Google Map API, then store it in a storage as an image. This data gathering was carried out once a minute for ten minutes.

The function of data processing section was to analyse and convert obtained density map image into density figures, then look for the values of density and density trends in ten minutes of gathering time. The time adjustment section had a function to adjust green-time duration based on the average density value and density trend value. The lamp control process was designed to control traffic lights signal. This process utilized green-time duration data from data processing process as a 


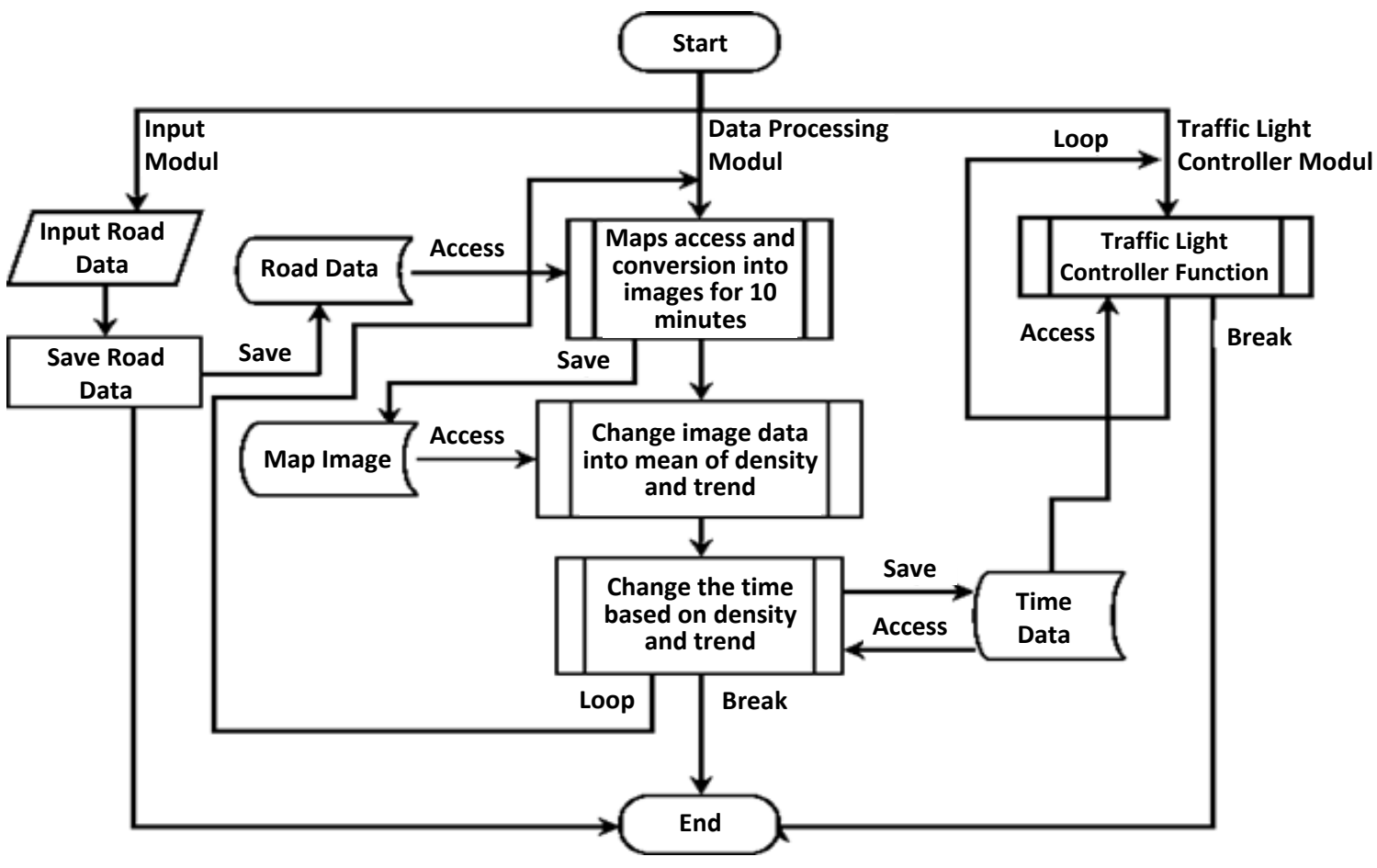

Fig. 2 Flowchart of the adaptive control system scheme.

duration of green signal. Duration of red and yellow signals had a fixed value of three seconds for yellow signal and two seconds for red signal [9].

\section{PROCESS OF TRAFFIC Lights CONTROL}

\section{A. Map Image Access and Processing}

The controlling system accessed density map from Google through the web page, because the Google Map API used to access density map could only be used through a HTML web page. This web page was used to access road density actual data using the Google Map API. The obtained density data was in a form of road density map in colour. In order to make the system able to process image more easily, this map from google would be customized so that it only displayed the colour of road density using JavaScript.

This web page was then converted into an image. This density map image was analysed based on the existing density colour using an OpenCV. The OpenCV is a Python library used for image processing. In this system, only the road density in the left lane was taken into account. For this reason, this image processing was done to cut the road's left lane from the map image. The stages of image processing to the road density map image are shown in Fig. 3.

Fig. 3(a) is the original image obtained from the Google Map API. Background of this image was then erased so that it looks like Fig. 3(b). Fig. 3(c) shows an image thresholding process. This process was carried out to convert images into black and white images. Fig. 3(d) is a process to determine objects on a map using edge detection. The next process was object filtration by removing all objects other than the two lanes as shown in Fig. 3(e). Then, the left lane was cut and converted to polygons as shown in Fig. 3(f). This image was then used as a mask for Fig. 3(a) in order to obtain the colour density data from left lane in the map image. This result is shown in Fig. 3(g).

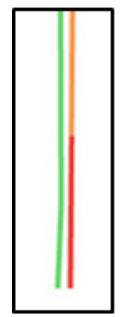

(a)

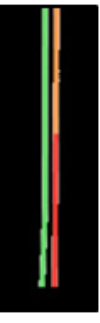

(b)

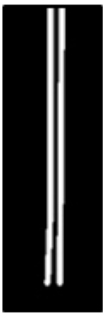

(c)

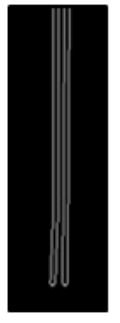

(d)

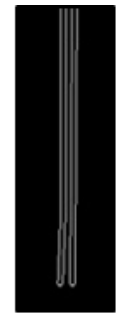

(e) (f)

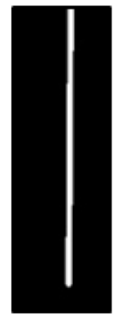

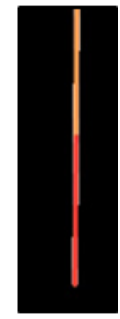

(g)
Fig. 3 Image processing stages to obtain density figures.

The road density figures was calculated based on (1).

$$
Q=\sum_{n}^{i=1}\left(p_{i} / n p\right) \times \omega
$$

with $Q$ was the density figures, $p$ was the number of pixels of the colour density, $n p$ was the available total pixel, and $\omega$ was the colour point. Colour point is density level of each colour available on the map. This density map values are 1 (the lowest) to 4 (the highest). The value of colour point is shown in Fig. 4.

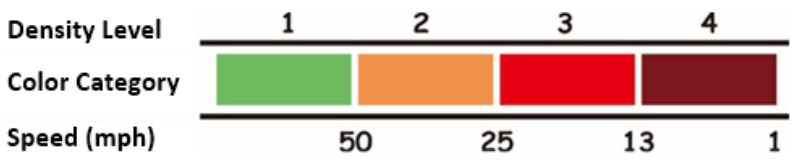

Fig. 4 Density level based on colour [10], [11].

Density data for 10 minutes of gathering period were used as a basis for obtaining density value and trend value. Density 
value was obtained by calculating the average of the density data, while the trend value or tendency value was obtained by using linear regression method.

\section{B. Adjustment of Green-Time Duration}

The adjustment of green-time duration was carried out in two stages. The first was to find the value of time adjustment and the second was to apply the time adjustment value into the previous time.

In the first stage, the system searched for time adjustment value based on density value and trend value. Time adjustment value is a value that must be applied to the previous time data to obtain a new time data.

The time adjustment value was divided into several types based on the conditions of obtained density and trend values. The conditions of density and trend values were each divided into three categories, so that time adjustment has a same value as the combination of the sum of the two, i.e., nine types. Table I displays nine-time adjustment values that occur.

TABLE I

VALUE OF TIME ADJUSTMENT

\begin{tabular}{|c|c|c|c|c|}
\hline \multirow{2}{*}{\multicolumn{2}{|c|}{ Category }} & \multicolumn{3}{|c|}{ Density Value } \\
\hline & & \multirow{2}{*}{$\begin{array}{c}\begin{array}{c}<1.6 \\
\text { (Light) }\end{array} \\
-10 \mathrm{~s}\end{array}$} & \multirow{2}{*}{$\begin{array}{c}\begin{array}{c}1.6-2.4 \\
\text { (Moderate) }\end{array} \\
-5 \mathrm{~s}\end{array}$} & \multirow{2}{*}{$\begin{array}{c}\begin{array}{c}>2.4 \\
\text { (Heavy) }\end{array} \\
+0 \mathrm{~s}\end{array}$} \\
\hline \multirow{3}{*}{ 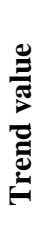 } & $\begin{array}{c}<-0.05 \\
\text { (Decrease) }\end{array}$ & & & \\
\hline & $\begin{array}{c}-0.05 \\
-0.05 \\
\text { (Constant) }\end{array}$ & $-5 s$ & $+0 \mathrm{~s}$ & $+5 \mathrm{~s}$ \\
\hline & $\begin{array}{c}>0.05 \\
\text { (Increase) }\end{array}$ & $+0 \mathrm{~s}$ & $+5 \mathrm{~s}$ & $+10 \mathrm{~s}$ \\
\hline
\end{tabular}

In the second stage, the obtained time adjustment values were then applied into previous time data to obtain a new time data. The application of time adjustment value could not be added directly, because the green-time duration in traffic lights control system was limited with a minimum green-time duration and a maximum green-time total duration. Value of those two are 13 seconds and 160 seconds respectively for Pogung four-way intersection [9], [12].

\section{Traffic Light Control}

This process ran simultaneously with a series of image analysis process to time duration adjustment. In this process, system controlled signals from traffic lights based on the available time duration data. The time duration for green signal was obtained from green-time duration data file from image processing process. When the system updated the green-time data based on the current road condition, the controller process would access the new green-time data then adjust time duration of green signal based on the new data.

\section{Simulation AND Results AnAlysis}

A system simulation was carried out by running this adaptive control system to control an intersection for 24 hours. The controlled intersection was Pogung four-way intersection, Yogyakarta.

This intersection consists of four streets, i.e., southern part of Monjali St., Jembatan Baru UGM St., northern part of
Monjali St., and Jati Mataram St. During the simulation, density value, trend value and green-time duration from each street branch in this intersection were stored as a simulation results data.

The analysed simulation results data were density data, trend value data, and time adjustment data from the northern section of Pogung four-way intersection. This data was considered to represent all occurring time adjustment inside the system because the time adjustment value at all street sections were obtained based on density and trend data by using a same equation.

The simulation data was presented based on the data gathering period, with one data gathering period was defined as a series of process in a system consisting of map image capturing for 10 minutes, density and trend values searching, time adjustment value setting, and the time adjustment value application to obtain the new time data.

The research was considered to be successful when the system could access map image with Google Map API, convert it into density data, calculate the density and trend values based on the obtained density data, and then adjust the green-time duration based on the density and trend values.

To test the system's success in adapting the time duration, an analysis on the obtained data of system's simulation results was carried out. This analysis on simulation results data was divided into two. The first was a testing analysis on each data by looking at the system's success in adjusting time duration based on the density and trend values. And the second was a testing analysis on the comprehensive simulation results data by finding a correlation between density and trend values with time duration.

\section{A. Time Adjustment}

In the first test, the adaptive system was considered to be successful if the occurring time adjustment corresponded to the time adjustment value based on the density and trend values. Data analysis was carried out by comparing the obtained adjustment value with the occurring time difference. Based on the category of density and trend values, the occurring time adjustment value was divided into nine types. Table II shows some examples of simulation data results from the northern street of Pogung four-way intersection based on the available nine types of time adjustment.

Table II shows several simulation results data in nine conditions of density and trend values that produce nine types of time adjustment values. Table II shows that the system has successfully adjusted time duration based on the density and trend values using time adjustment value categorization in Table I.

After the system obtained the time adjustment value, that adjustment value could not be directly added into the previous time data. The system had to ensure that the time duration of each road side was no less than 13 seconds and the total of entire time duration did not exceed 160 seconds.

The data of simulation results shows that there is no time duration that is less than 13 seconds and the total of the entire time duration does not exceed the 160 seconds limit. This indicates that the system has successfully adjusted the greentime duration without exceeding the predetermined limit value. 
TABLE II

DATA EXAMPLE OF SimUlation RESUlts OF NORTHERN STREET BASED ON THE VALUES OF DENSITY AND TREND

\begin{tabular}{|c|c|c|c|c|c|c|c|}
\hline $\begin{array}{c}\text { Condition } \\
\text { Number }\end{array}$ & $\begin{array}{c}\text { Data Gathering } \\
\text { Period }\end{array}$ & $\begin{array}{c}\text { Density } \\
\text { Value }\end{array}$ & $\begin{array}{c}\text { Trend } \\
\text { Value }\end{array}$ & $\begin{array}{c}\text { Time Adjustment Value } \\
\text { (s) }\end{array}$ & $\begin{array}{c}\text { Preceding Time } \\
\text { (s) }\end{array}$ & $\begin{array}{c}\text { Following } \\
\text { Time (s) }\end{array}$ & $\begin{array}{c}\text { Time Difference } \\
\text { (s) }\end{array}$ \\
\hline 1 & 11 & 1.468 & -0.080 & -10 & 30 & 20 & -10 \\
\hline 2 & 16 & 1.456 & 0.008 & -5 & 25 & 20 & -5 \\
\hline 3 & 31 & 1.463 & 0.079 & 0 & 40 & 40 & 0 \\
\hline 4 & 138 & 2.373 & -0.158 & -5 & 24 & 19 & -5 \\
\hline 5 & 14 & 1.845 & -0.031 & 0 & 25 & 25 & 0 \\
\hline 6 & 135 & 1.877 & 0.066 & +5 & 19 & 24 & +5 \\
\hline 7 & 48 & 3.106 & -0.091 & 0 & 49 & 49 & 0 \\
\hline 8 & 21 & 3.201 & 0.038 & +5 & 30 & 35 & +5 \\
\hline 9 & 23 & 3.033 & 0.098 & +10 & 35 & 45 & +10 \\
\hline
\end{tabular}

\section{B. Correlation Analysis}

The second test was an analysis of the entire data. In this test, this adaptive system was considered to be successful when there was a correlation between the density and trend values with the green-time duration. The data analysis was performed by finding the correlation coefficient between the density and trend values with green-time duration.

This correlation coefficient was obtained using multiple correlation method. This method was employed because the simulation results data consisted of two independent variables (density and trend values) and one dependent variable (greentime duration). Correlation coefficient values can be discovered using (2).

$$
R=\sqrt{\frac{r^{2} X_{1} Y+r^{2} X_{2} Y^{-2} \cdot r_{X_{1} Y} \cdot r_{X_{2} Y} \cdot r_{X_{1} X_{2}}}{1-r^{2} X_{1} X_{2}}}
$$

with $r_{X Y}$ are simple correlation between $X$ and $Y$ variables. The value of $r_{X Y}$ can be calculated with (3).

$$
r_{X Y}=\frac{n\left(\sum X Y\right)-\left(\sum X\right)\left(\sum Y\right)}{\sqrt{\left\{n \cdot \sum X^{2}-\left(\sum X\right)^{2}\right\} \cdot\left\{n \cdot \sum Y^{2}-\left(\sum Y\right)^{2}\right\}}}
$$

with $n$ is the data number of each variable, $\sum X$ is the number of $X$ variable, $\sum Y$ is the number of $\mathrm{Y}$ variable, $\sum X^{2}$ is the number of the squares of the $\mathrm{X}$ variable, $\sum Y^{2}$ is the number of the squares of the $Y$ variable, and $\sum X Y$ is the number of $X$ variable multiplied by $Y$ variable.

Based on (2) and (3), the obtained value of correlation coefficient between density and trend values and time duration is of 0.740 . This coefficient indicates that the existing correlation value is quite robust. A positive correlation coefficient value shows that this correlation is unidirectional. The significance test shows a significant correlation between density value and trend value on the green-time adjustment. This second test proves that changes in density and trend values on the street have a robust and significant influence on the occurring time duration adjustment.

\section{CONCLUSION}

In this paper, a prototype of an adaptive control system has been made. This prototype is able to gather traffic density data with Google Map API and then adjust the duration of traffic lights based on the density data. Based on the conducted test, the obtained results show that the green-time duration fluctuates due to changes in the values of density and trend values. This shows that this adaptive traffic lights control system has successfully adjusted traffic lights settings to the actual conditions of the road density. It is also obtained that density value and density trend has a significant correlation with the green-time duration. The existing correlations are unidirectional. For that reason, it can be concluded that the occurring time adjustment is influenced by the density value and trend value.

\section{ACKNOWLEDGEMENTS}

Thank you to the team of fellow developers who have worked hard in making this adaptive regulatory system and also thank you to laboratory colleagues who have helped a lot.

\section{REFERENCES}

[1] U. Arieza (2018) "Indonesia Penduduk Terbanyak Nomor 4 di Dunia, Siapa Juaranya?: Okezone Economy," [Online], https://economy.okezone.com/read /2018/07/21/320/1925559/indonesiapenduduk-terbanyak-nomor-4-di-dunia-siapa-juaranya, access date: 08Nov-2018.

[2] J. Budiarto, S. Sulistyo, I.W. Mustika, and A. Infantono, "Road Density Prediction, Updated Methods of Turning Probabilities and Highway Capacities Manual for Achieving the Best Route,” 2014 International Conference on Electrical Engineering and Computer Science (ICEECS 2014), 2014, pp. 168-173.

[3] E.E. Prasetiyo, O. Wahyunggoro, and S. Sulistyo, "Desain Pengatur Lampu Lalu Lintas Adaptif Dengan Kendali Logika Fuzzy," Seminar Nasional Teknologi Informasi dan Multimedia 2015, 2015, pp. 3.7-1-6.

[4] M. Tubaishat, Y. Shang, and H. Shi, “Adaptive Traffic Light Control with Wireless Sensor Networks,” 2007 4th IEEE Consumer Communications and Networking Conference, 2007, pp. 187-191.

[5] S. Kwatirayo, J. Almhana, and Z. Liu, “Adaptive Traffic Light Control using VANET: A Case Study,” 2013 9th International Wireless Communications and Mobile Computing Conference (IWCMC), 2013, pp. 752-757.

[6] J. Li, Y. Zhang, and Y. Chen, “A Self-Adaptive Traffic Light Control System Based on Speed of Vehicles," 2016 IEEE International Conference on Software Quality, Reliability and Security Companion (QRS-C), 2016, pp. 382-388.

[7] S. M. Shinde, “Adaptive Traffic Light Control System,” 2017 1st International Conference on Intelligent Systems and Information Management (ICISIM), 2017, pp. 300-306. 
[8] N. Rida, M. Ouadoud, A. Hasbi, and S. Chebli, “Adaptive Traffic Ligh Control System Using Wireless Sensors Networks,” 2018 IEEE 5th International Congress on Information Science and Technology (CiSt), Marrakech, Morocco, 2018, pp. 552-556.

[9] MnDOT Traffic Signal Timing and Coordination Manual, Minnesota Department of Transportation, 2017.

[10] (2018) "View places, traffic, terrain, biking, and transit - Computer Google Maps Help,” [Online], https://support.google.com/maps/ answer/3092439, access date: 17-Mar-2018.
[11] J. Stevens (2013) "Joshua Stevens - Your Favorite Traffic Map is Lying to You,” [Online], http://www.joshuastevens.net/design/your-favoritetraffic-map-is-lying-to-you/, access date: 17-Mar-2018.

[12] K.-L. Bang, "Final Report: Indonesian Highway Capacity Manual and Software (Kaji),” Directorate General Bina Marga, Directorate of Urban Road Development (Binkot), Indonesia, 3860, Feb. 1997. 